\title{
Long-Term Storage of Ustilago tritici
}

\author{
J. G. Menzies, Research Scientist, J. Nielsen, Research Scientist (Retired), and P. L. Thomas, Research Scientist \\ (Retired), Cereal Research Centre, Agriculture and Agri-Food Canada, 195 Dafoe Road, Winnipeg, Manitoba, Can- \\ ada, R3T 2M9
}

\begin{abstract}
Menzies, J. G., Nielsen, J., and Thomas, P. L. 1997. Long-term storage of Ustilago tritici. Plant Dis. 81:1328-1330.

An extensive collection of isolates of Ustilago tritici from around the world is maintained at the Cereal Research Centre. As the collection size increases, however, the time and effort needed to maintain the collection becomes greater, as does the need for a good technique for long term storage of $U$. tritici. Race T2 of U. tritici was inoculated to spikelets of wheat in February 1976. The matured inoculated heads were thrashed and the seed stored in a desiccator with silica-gel at $-15^{\circ} \mathrm{C}$. Every 2 years, 60 seeds were removed and planted to determine viability and proportion of infected adult plants. Between 57 and $83 \%$ of the seed produced adult plants, and the percent of infected plants ranged between 56 and $98 \%$ during the 20 years. There was no significant change in seed germination over time, but there was a positive relationship $(P<0.0664$, $R^{2}=0.452$ ) between the time of storage and the arcsine of the proportion of smutted plants. Storage of $U$. tritici in infected seed at $-15^{\circ} \mathrm{C}$ and low relative humidity is an efficient method for long-term storage of this fungus.
\end{abstract}

Hanna and Popp (3) were the first researchers to demonstrate the existence of races of Ustilago tritici (Pers.) Rostr. in North America. Since that time, smut pathologists at the Cereal Research Centre (CRC), Winnipeg, Manitoba, have screened many different isolates of the fungus to determine the race composition of natural populations of $U$. tritici in western Canada and other parts of the world $(2,4,6,8)$. This work has been important in aiding wheat breeders to determine which resistance genes are necessary for incorporation into new wheat lines, and allowing plant pathologists to study virulence shifts in natural pathogen populations. The collected races of $U$. tritici have also been useful in genetic studies of the host and pathogen (5). Unfortunately, as new races of the fungus are found and as collections of isolates of similar race from different parts of the world get larger, it becomes

Corresponding Author: J. G. Menzies E-mail: jmenzies@em.agr.ca

Cereal Research Centre Contribution No. 1691.

Accepted for publication 13 July 1997.

Publication no. D-1997-0902-02S

This article is in the public domain and not copyrightable. It may be freely reprinted with customary crediting of the source. The American Phytopathological Society, 1997. laborious and time consuming to preserve the collections.

Wheat spikes with sori of the different $U$. tritici races are usually dried and stored at the CRC in glass jars at 2 to $4^{\circ} \mathrm{C}$ (4). Spores stored in such a manner can survive at acceptable germination rates (greater than $50 \%$ ) for periods up to 16 years (Table $1)$, but the results are variable. After storage in glass jars for 16 years, races such as T17 and T18 had germination rates of 60 to $80 \%$, while races such as $\mathrm{T} 7, \mathrm{~T} 8$, and $\mathrm{T} 10$ had germination rates of less than 1 to $5 \%$. Race $\mathrm{T} 13$ had a germination rate of only $10 \%$ after 11 years of storage in glass jars, and races $\mathrm{T} 4$ and $\mathrm{T} 26$ had germination rates of 45 and $50 \%$, respectively, after only 7 years of storage, suggesting that they should be rejuvenated soon. In general, teliospores of $U$. tritici and other smut fungi stored in glass jars at 2 to $4^{\circ} \mathrm{C}$ should survive for at least 5 years $(4,12)$, but one cannot be confident of good spore survival beyond 10 years of storage in this manner. Since host reinfection and subsequent increase of teliospores of an isolate or race of $U$. tritici is laborious and time consuming, a longer-term storage technique is desirable.

The long-term storage of isolates of Ustilago spp. as mycelium in infected seed has been previously suggested. Tapke (13) found that barley seed infected with $U$. nuda (C.N. Jensen) Rostr. (Syn. U. nuda (C.N. Jensen) Kellerm. \& Sw.) and stored at -2 to $0^{\circ} \mathrm{C}$ was viable after 7 years of storage, and $73 \%$ of the plants grown from the seed produced sporulating sori (for simplicity, such plants will be termed "infected"). Russell (11) stored seed infected with $U$. nuda in glass jars at room temperature and found that some samples showed a reduction in the percent of infected plants grown from the seed after 6 years of storage, while others showed little reduction until the samples were in storage for 10 years. This decline was attributed to reduced germination of infected seed because of weaker embryos (11). Roszko et al. (10) found that mycelium of $U$. nuda in infected seed survived only a short period of time and concluded that in order to obtain a sufficiently viable inoculum with simultaneously high seed germination, the period of storage should not exceed 2 years. In addition, the percent infection of the host seed decreased with longer storage. Tiemann (15) observed that the level of infection decreased only slightly in plants grown from seed infected with $U$. tritici which had been stored at room temperature for 3 years. Perhaps more importantly, Buchheim (1) found that storage of wheat seed below $0^{\circ} \mathrm{C}$ had no effect on the level of loose smut infection in the plants grown from such seed. The findings of Buchheim along with the prediction that the viability of wheat seed stored at $-20^{\circ} \mathrm{C}$ and 5\% moisture content would drop only $5 \%$ in 78 years (9) prompted us to develop a technique for the long term preservation of isolates of $U$. tritici.

\section{MATERIALS AND METHODS}

Race T2 (4) of $U$. tritici was inoculated to spikelets of the wheat differential TD-3 (Florence $\times$ Aurore; 4) in February 1976, using a hypodermic needle and syringe and an inoculum concentration of approximately $1 \mathrm{~g}$ of teliospores/liter water $(4,7)$. The matured inoculated heads were thrashed, and the seed was placed in a desiccator with silica-gel and kept at room temperature for one week. During this period, 60 seeds were removed and planted in soil beds in the greenhouse to determine the percent germination of the seed and the percent infected plants. The desiccator and remaining seed then were placed in a freezer at $-15^{\circ} \mathrm{C}$ for storage. Every 2 years, 60 seeds were removed from storage and planted in soil beds in the greenhouse to 


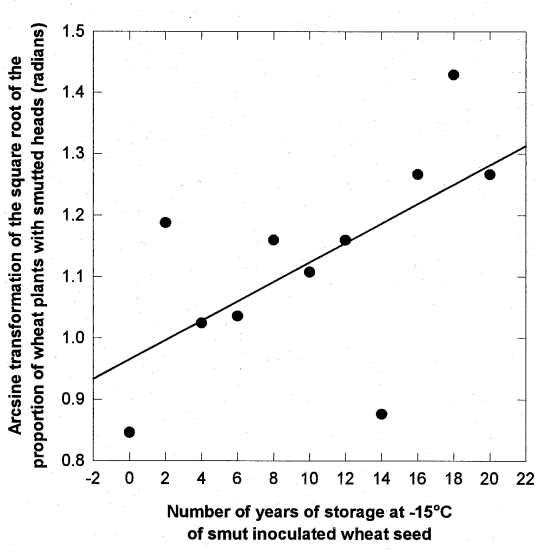

Fig. 1. The effect of long-term storage at $-15^{\circ} \mathrm{C}$ of wheat seed (differential TD-3 [Florence $x$ Aurore]) infected with race T2 of Ustilago tritici on the subsequent proportion of plants with smutted heads arising from the seed $(P<$ $0.0664, R^{2}=0.452$ ).

Table 1. Germination ${ }^{\mathrm{a}}$ of teliospores of different races of Ustilago tritici stored at 2 to $4^{\circ} \mathrm{C}$ in glass jars

\begin{tabular}{lcc}
\hline Race of Ustilago tritici & Date smutted heads harvested & Percent germination of teliospores \\
\hline T1 & April 1980 & 10 \\
T7 & April 1980 & $<1$ \\
T8 & November 1980 & 1 \\
T10 & November 1980 & 5 \\
T17 & November 1980 & 60 \\
T18 & November 1980 & 80 \\
T2 & May 1981 & 5 \\
T15 & June 1981 & 1 \\
T27 & February 1981 & 80 \\
T19 & January 1982 & 5 \\
T28 & January 1982 & 80 \\
T30 & January 1982 & 20 \\
T35 & January 1982 & 40 \\
T25 & September 1983 & 60 \\
T6 & December 1985 & 80 \\
T16 & April 1985 & 40 \\
T13 & April 1985 & 10 \\
T3 & 1989 & 85 \\
T4 & 1989 & 45 \\
T26 & 1989 & 50 \\
T22 & May 1990 & 90 \\
T9 & June 1993 & 85 \\
\hline
\end{tabular}

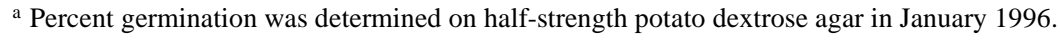

Table 2. Percentage of plants produced and subsequent percentage of smutted plants from 60-seed samples of wheat differential TD-3 (Florence $\times$ Aurore) inoculated with race T2 of Ustilago tritici and stored at $-15^{\circ} \mathrm{C}$ since 1976

\begin{tabular}{lcc}
\hline Number of years in storage & $\begin{array}{c}\text { Percentage of seed that } \\
\text { produced adult plants }\end{array}$ & $\begin{array}{c}\text { Percentage of adult plants } \\
\text { infected by } \text { Ustilago tritici }\end{array}$ \\
\hline 0 & 57 & 56 \\
2 & 82 & 86 \\
4 & 80 & 73 \\
6 & 65 & 74 \\
8 & 83 & 84 \\
10 & 77 & 80 \\
12 & 82 & 84 \\
14 & 82 & 59 \\
16 & 75 & 91 \\
18 & 67 & 98 \\
20 & 78 & 91 \\
\hline
\end{tabular}

$<0.0664, R^{2}=0.452$ ) between the time of storage and the arcsine transformation of the square root of the proportion of smutted/healthy plants (Fig. 1), but not between the time of storage and the other parameters. If this relationship is real, the mechanism for the increase in the proportion of smutted heads is not clear, but the survival and/or growth of Ustilago tritici within infected seed or germinating seedlings may be enhanced by the cold storage treatment.

Levels of smutted plants from infected seed are notoriously variable (14), probably because of the early stages of plant growth being affected by uncontrollable variables in soil beds in greenhouses or the field. The variability in infection levels observed in Table 2 probably reflects the variability that is normally observed after growing inoculated seed. It is expected that the percentage of infected plants will remain high (greater than 50\%) for decades. It should be noted that this experiment is ongoing, and it is hoped that we will be able to collect data on storage of $\mathrm{T} 2$ for another 30 to 40 years. A larger population of infected seed samples would have enabled replication and a more critical examination of germination/infection levels. However, the population used is adequate to illustrate the eventual decline in germination/infection over a long time period, and allows future investigators to minimize the resources needed to continue this work. Currently, in order to conserve labor and storage facilities, all races of $U$. tritici and $U$. nuda are being stored in this manner at the CRC. Long term storage at $-15^{\circ} \mathrm{C}$ of the different races and isolates of these pathogens in infected seed consumes much less time and space than traditional storage techniques.

\section{LITERATURE CITED}

1. Buchheim, A. N. 1935. Effect of freezing on the germinability of wheat seeds infected with loose smut, and on the development of plants raised from them. Plant Prot. (Leningrad) 6:134-137.

2. Cherewick, W. J. 1958. Cereal smut races and their variability. Can. J. Plant Sci. 38:481489.

3. Hanna, W. F., and Popp, W. 1932. Physiological forms of loose smut of wheat. (Abstr.) Phytopathology 22:11.

4. Nielsen, J. 1987. Races of Ustilago tritici and techniques for their study. Can. J. Plant Pathol. 9:91-105.

5. Nielsen, J. 1988. Ustilago spp., Smuts. Advances in Plant Pathology 6:483-490.

6. Nielsen, J., and Thomas, P. L. 1982. Races of loose smut of wheat in south Australia. Australas. Plant Pathol. 11:53.

7. Nielsen, J., and Thomas, P. L. 1996. Chapter 4. Loose Smut. Pages 33-47 in: Bunt and Smut Diseases of Wheat: Concepts and Methods of Disease Management. R. D. Wilcoxson and E. E. Saari, eds. Mexico, D.F.

8. Nielsen, J., and Tikhomirov, V. 1993. Races of Ustilago tritici identified in field collections from eastern Siberia using Canadian and Soviet differentials. Can. J. Plant Pathol. 15:193-200.

9. Roberts, E. H., and Ellis, R. H. 1977. Prediction of seed longevity at sub-zero tempera- 
tures, and plant genetic resources conservation. Nature 268:431-433.

10. Roszko, A., Kozera, W., and Kwater, S. 1980. The time of storage of artificially infected grain of barley and its effect on the viability of the mycelium of Ustilago nuda (Jens.) Rostr. Acta Agrar. Silvestria Ser. Agrar. 19:161-169.
11. Russell, R. C. 1961. The influence of aging of seed on the development of loose smut in barley. Can. J. Bot. 39:1741-1746.

12. Sampson, K. 1928. The biology of oat smuts. I. Viability of the chlamydospores. Ann. Appl. Biol. 15:586-612.

13. Tapke, V. F. 1955. Physiological races in Ustilago nuda and techniques for their study.
Phytopathology 45:73-78.

14. Thomas, P. L. 1991. Genetics of small grain smuts. Annu. Rev. Phytopathol. 29:137-148.

15. Tiemann, A. 1925. Untersuchungen über die Empfänglichkeit des Sommerweizens für Ustilago tritici, und der Einfluss der äusseren Bedingungen dieser Krankheit. Kühn-Archiv 9:405-467. 